\title{
Why Do Albania Doctors Migrate?
}

\author{
Gazment Koduzi \\ MD, Ass. Prof. "Aleksander Xhuvani" University, Elbasan \\ Senior Researcher Healthgrouper
}

MSc, Ardita Kongjonaj

Senior Researcher Healthgrouper

MD, MSc Vladimir Lazarevik

\begin{abstract}
Migration has become a very topical political and economic concern over the past few years, with particular reference to human migration from developing countries to more developed countries. Health workforce migration from the countries in Western Balkans, especially from Albania to more developed countries is increasing during the past few years according to official statement of medical associations. So, last three years 400 doctors have asked for certificate of "Good standing" in order to apply for a job abroad. Thus, the migration of healthcare personnel in Albania is becoming a phenomenon that might risk the stability of the healthcare system with its upgrading intensity. It also contributes to lowering the quality of services rendered and at the same time reduces the necessary transfer of knowledge to the younger generations. Quantitative research performed during 2014, outlines and frames the problems and causes for the migration in five basic categories: economic, professional, political, personal and social factors for migration, including questions concerning the index of satisfaction for the profession. In order to respond to the objective of the study, doctors were invited by email to fill online the questionnaire in Survey Monkey webpage. The aim of this paper is to understand the "push" factors which affect the mobility of Albanian healthcare personnel. The needs for higher income, living and working conditions are the main causes of the expansive trend of migration of healthcare workers from Albania in the past several years. Still, the reasons behind migration of health workforce are multifold, ranging from economic and professional, to political and personal factors. The lack of job satisfaction and possibilities for further education and career development, poor working conditions, political pressure, the exposure to verbal and physical violence, are also the factors that stimulate the migration.
\end{abstract}

Keywords: Albania, health workforce, migration, factors, higher income, professional development

\begin{abstract}
Introduction
Albania has experienced massive migration since in early 1990 immediately after the communist regime has fallen, whereas one third of Albanian population leaves abroad (Nurja 2011). Albanian healthcare system is one of the sectors most affected by massive migration of population where health staff is part of this massive movement. So, according to Order of Physicians there are 400 doctors have asked for "Certificate of good standing" in order to go and work abroad ${ }^{1}$. As consequence of massive migration and other factors Albania has the lowest rate of medical doctors for covering healthcare to population, by 1.1 doctors for 1000 inhabitants. Taking in consideration very low ration of population coverage by medical service and number of doctors leaving country to migrate to other countries, it is a small production of doctors in Albania. Thus, there are two medical faculties situated in Tirana and total students graduated last five years is 1141 (Table 1). The number of students graduated each year can't replace number of doctors retired, leaving the country, shifting from public service to private practice. This will require other options from government in order to fulfill the need of the system for medical doctors.
\end{abstract}

\footnotetext{
${ }^{1}$ Order of Physician 2016
} 
Table 1. Basic indicators for Albania

\begin{tabular}{|l|l|l|}
\hline Indicator & Value & Remark (e.g. year) \\
\hline Total population & $2,886,026$ & INSTAT 2016 \\
\hline GDP per capita & 11,900 PPP USD ${ }^{1}$ & World Bank 2015 \\
\hline Health expenditure as \% GDP & $6 \%$ & WHO, World health statistics 2014 \\
\hline Health expenditure (in US \$) & 534 PPP int. \$ & WHO, World health statistics 2014 \\
\hline Number of doctors & 7708 & \\
\hline Number of specialists & 3960 & 2016 \\
\hline Number of medical universities / faculties & 2 & 2016 \\
\hline Number of graduated medical students & 1141 & 2016 \\
\hline
\end{tabular}

According to Lee's Push and Pull Theory ${ }^{2}$ migration is likely to occur when the plusses at the destination outweigh the plusses of staying at the origin. Using this theory, this paper inventories those "plus factors" of the destination country as compared with the "plus factors" remaining in the home country (Albania) regarding doctors' migration.

\section{Methodology}

In the framework of this study are selected and analyzed six main groups of factors behind mobility of health workforce: employment opportunities, salary, working conditions, career opportunities, social status and living conditions. These push or pull factors are analyzed for the three groups of respondents: doctors who already migrated, potential migrants abroad, and potential internal migrants who participated in the survey specially designed and conducted for the purposes of the project. An on-line questionnaire was available in albanian language, and over 254 doctors from Albania and abroad responded. The total number of completed responses was 210 with response rate $83 \%$.

\section{Findings}

Albania has faced huge migration of population since early 1990, where around one third of population (1.4 million) moved abroad $^{3}$. Parts of these phenomena were even healthcare workers, as social strata which suffered a lot during transition. In table 2 of this paper is presented the socio-demographic characteristic of the interviewed doctors.

\section{Table 2. Socio-demographic characteristic of the sample}

\begin{tabular}{|l|l|l|}
\hline Category & Sub-category & $\%$ \\
\hline Sex & Female & 58.6 \\
& Male & 41.4 \\
\hline Age (years) & $<36$ & 54.2 \\
& $36-45$ & 27.3 \\
& $>45$ & 18.5 \\
\hline Family Status & Married & 64.8 \\
& Not married & 35.2 \\
\hline
\end{tabular}

\footnotetext{
${ }^{1}$ Index mundi 2016

${ }^{2}$ Lee, E. 1966. A theory of migration. Demography 3(1), 47-57.

${ }^{3}$ Albanian Census 2011
} 


\begin{tabular}{|l|l|l|}
\hline Have children & Yes & 60.3 \\
& No & 39.7 \\
\hline Profession & Specialist & 50.9 \\
& Specialist-in-training & 8.3 \\
& General physician & 40.7 \\
\hline
\end{tabular}

Most of the interviewers belong to specialized doctors, age cohort younger than 36 years old, married and female. Most of potential migrants see living conditions and working conditions as main factors that influence their migration from Albania to other countries which offer better conditions (Table 3).

\section{Table 3. Factors that influence migration of doctors from Albania}

\begin{tabular}{|l|l|l|l|l|}
\hline \multicolumn{2}{|l}{ Factors that influence migration } & \multicolumn{3}{l|}{} \\
\hline Very important & Migrants & $\begin{array}{l}\text { Potential migration } \\
\text { abroad }\end{array}$ & Internal migration & Unemployed \\
\hline Working conditions & 88.2 & 72.5 & 67.6 & 64.3 \\
\hline Career opportunities & 58.8 & 54.5 & 64.9 & 71.4 \\
\hline Social status & 47.1 & 55.7 & 47.3 & 21.4 \\
\hline $\begin{array}{l}\text { Economic situation in } \\
\text { the city you live in }\end{array}$ & 35.3 & 50 & 57.4 & 64.3 \\
\hline $\begin{array}{l}\text { Employment } \\
\text { opportunities }\end{array}$ & 64.7 & 68.6 & 64.9 & 85.7 \\
\hline Living conditions & 82.4 & 78.6 & 66.2 & 71.4 \\
\hline
\end{tabular}

The factors that influence the migration of doctors are different for four groups of respondents: migrants, potential migrants, inner migrants and unemployed.

On the other hand, different groups have some similarity in pushing factors. So, working conditions and living conditions are factors that affect mostly decision of migrants and potential migrants to leave the country. Unemployed doctors are motivated to migrate because of employment opportunities, living conditions and career opportunities, as most important issues for them. Doctors thinking to move into other cities inside the country are motivated by working conditions, living conditions, career opportunities and employment opportunities as factors they can't fulfill in their present city. By analyzing data according to six groups of factors which influence migration of doctors abroad for each group of doctors, we can have better picture of main "push" factors. So, in graph 1 we see that salary is the most important factor that influence decision making to move abroad. This happen because average salary for specialists in Albania is 414 Euro/month ${ }^{1}$ which is less than average salaries in other regional countries ${ }^{2}$.

\footnotetext{
${ }^{1}$ Health Insurance Fund 2012

2 European Hospital Doctors' Salaries, Enrico Reginato, Rosario Grosso, 2011 
Graph 1: Factors that influence potential migrants to consider leaving home country

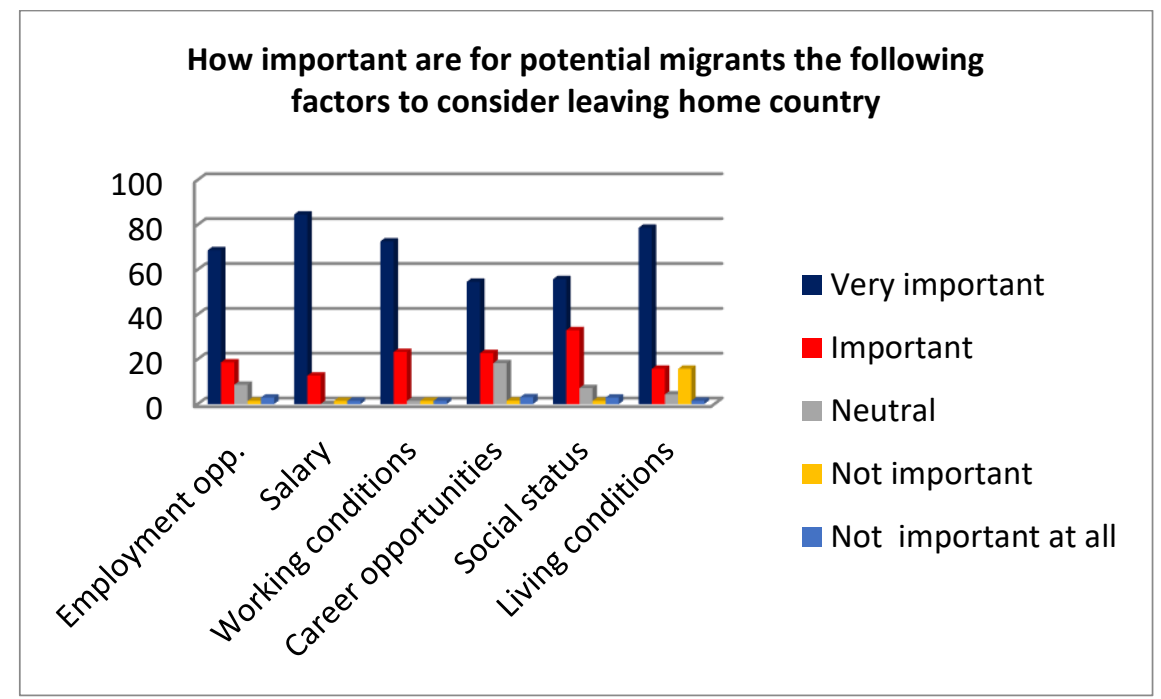

Another important factor influencing decision to leave home country is working condition (Graph 1). Unsatisfactory working condition is one of the reasons that decrease satisfaction of doctors at the working place. So $35 \%$ of interviewed (Graph 2) declare they are dissatisfied or not at all satisfied at the working place. According to motivation theory of Herzberg ${ }^{1}$ working conditions and salary level are factors for dissatisfaction or hygiene factors, which make doctors decide to leave home country.

Graph 2: Satisfaction of interviewed doctors at the working place

\begin{tabular}{|c|c|}
\hline & $\begin{array}{c}\text { Overall satisfaction as a doctor at the working } \\
\text { place }\end{array}$ \\
& Not at all \\
$27 \%$ & Satisfied \\
& Dissatisfied \\
& Neutral \\
$29 \%$ & Very satisfied \\
\hline
\end{tabular}

${ }^{1}$ Herzberg's Motivators and Hygiene Factors 
On the other hand, most important factors that influenced their decision to leave home country and work abroad were working conditions, leaving conditions and salary (Graph 3). These results reinforce the findings from the interviews of potential migrants who had salary and leaving conditions as main drivers to leave Albania.

\section{Graph 3: Importance of factors for migrant's decision to leave home country}

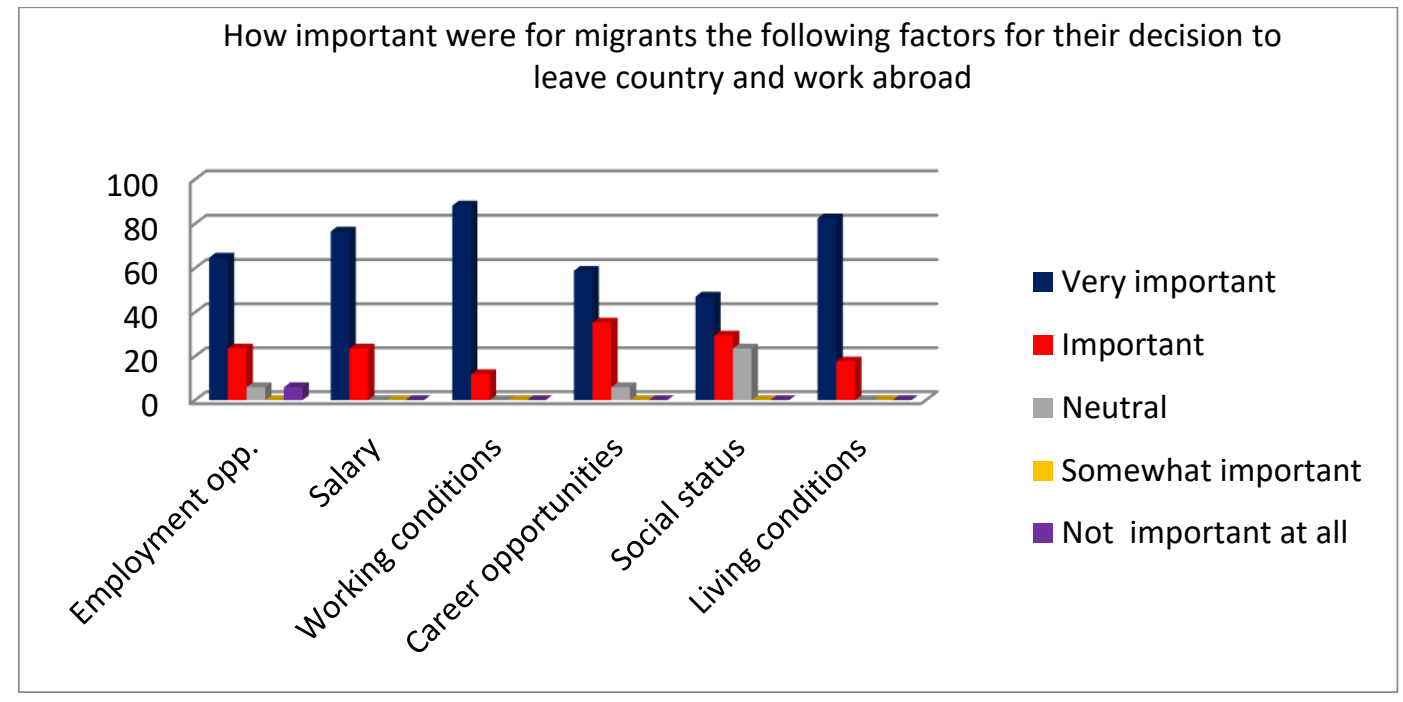

\section{Conclusion}

The increasing trend of health workforce migration from Albania endangers normal functioning and quality of services delivered by national health care systems. According to Order of Physician over 400 doctors from Albania left over the past years to work abroad. This number may increase in the following years, which brings this problem to be recognized and put in the center of development of further health and educational policies in these countries.

Based on research findings, the needs for higher income (better salary), better working and living conditions are the main causes of the expansive trend of migration of healthcare workers from Albania in the past several years. Still, the reasons behind migration of health workforce are multifold, ranging from economic and professional, to political and personal factors. The lack of job satisfaction and possibilities for career development, poor working conditions are also the factors that stimulate the migration. On the other hand, the main "pull" factors are attractive salaries, better possibilities for professional development and employment policies that recognize good performance.

Albanian institutions must take actions in order to stop the increased trend of the migration of the healthcare workers and protect the stability and quality of the healthcare system. Based on our research, the main recommendations for measures that need to be taken by institutions in order to improve the situation in the health system's, are:

To increase the investments in the health sector in order to improve the working environment

To increase the income level of doctors

To improve the access to quality program for healthcare workers

To improve the education infrastructure and continued education of the health workforce

Health workers migration is a serious condition that requires timely intervention from the concerned authorities. If appropriate recommendations are not taken, there will be serious consequences for healthcare system and population health in Albania. 


\section{References}
[1] Albanian Census 2011
[2] European Hospital Doctors' Salaries, Enrico Reginato, Rosario Grosso, 2011
[3] Health Insurance Fund 2012
[4] Health: Key tables from OECD - ISSN 2075-8480 - @ OECD 2014
[5] Herzberg's Motivators and Hygiene Factors
[6] Index mundi 2016
[7] Lee, E. 1966. A theory of migration. Demography 3(1), 47-57.
[8] Order of Physician 2016 